\title{
Neural Substrates of Vocalizations in Gulls and Pigeons ${ }^{1}$
}

\author{
Juan D. Delitus \\ Department of Neuroseiences, UCSD, La Jolla (U.S.A.) \\ and Department of Psychology, Durham (England) ${ }^{2}$
}

Summary. Vocalizations were obtained by electrically stimulating the inferior colliculus, the auditory thalamic nucleus and a medial hypothalamic nucleus of awake, unrestrained herring gulls, lesser black-backed gulls and pigeons. The significance of the involvement of auditory centres in the motor control of avian calling is discussed. The wide gammut of calls and accompanying behaviour that was elicited is described and related to the normal behaviour, typical of the species concerned. A difference between immature gulls and adult pigeons regarding this relationship is attributed to their differing hormonal states. Attention is drawn to the heterogeneity of temporal characteristics associated with the stimulus induced responses even when elicited from virtually the same site. Incorporating earlier work on the central mechanism of avian vocalizations and based on anatomical, physiological and behavioural considerations it is tentatively concluded that the neural structures involved are linearly organized into a telencephalofugal, efferent system. It is suggested that the inferior colliculus incorporates the origin of a final common pathway to medular motor centres for all vocalization generating structures.

Key Words: Electrical brain stimulation — Evoked vocalization — Birds

\section{Introduction}

Vocalizations play an important communicatory role within the social behaviour of birds. It is not surprising therefore, that they have been the subject of intensive research (Thorpe, 1958; Hinde, 1969). But only few of the studies, well summarized by J. Brown (1969) have been concerned with the neural mechanisms of avian sound production. These could, however, be of interest from various points of view.

Many bird calls are stereotyped but complexly patterned sounds; the neural substrate producing them might be suitable for studying the neurogenic generation of non-periodic patterns (Murphey and Phillips, 1967). The songs of some species are learned; the structures underlying them may be promising material for studying the neuronal changes that accompany learning (Konishi and Nottebohm, 1969). Some vocalizations are uttered only during certain hormonal states; hormones must be impinging on the vocalization mechanisms and hence these could

\footnotetext{
${ }_{1}^{1}$ Meinem hochverehrten Lehrer Professor Dr. G. Birukow, Göttingen, zu seinem 60. Geburtstag gewidmet.

2 Present address: Department of Psychology, Durham.
} 
be good sites for studying humoro-neural interactions (Hutchison, 1967). Bird individuals that could be induced with electrical stimulation to utter particular calls at specified times would be invaluable for the analysis of the communicatory function of vocalizations (John Smith, 1969). The fact that the avian syrinx differs fundamentally from the mammalian larynx (Greenwalt, 1969), in conjunction with the divergent brain organisation of the two vertebrate classes (Kappers, Huber and Crosby, 1965), provides an interesting background for a comparative study of the functional neurology of vocalizations.

Before such studies are possible it is necessary to identify and delineate with some precision the central nervous structures involved in controlling and patterning avian vocalization. This paper presents results relevant to this problem arising from a systematic exploration of the brain of herring and lesser black-backed gulls with electrical stimulation (Delius, 1967, in prep.) and some results of a more specific study on pigeons using the same technique, which expand the information obtained by earlier workers.

The work was supported by grants to Prof. N. Tinbergen, F.R.S. and myself, from the U.S. Air Force Office of Scientific Research through the European Office of Aerospace Research, the Science Research Council and the Royal Society. It was partly carried out at the Dept. of Zoology, Oxford. I wish to thank Mrs. J. McFarland, Dr. G. Thompson, Dr. R. G. B. Brown, Dr. J. Chou, Dr. P. Bateson, Mr. A. Jackson, Mr. J. Musser and Mrs. K. Bennetto for assistence at various times. Profs. T.H. Bullock, R. Galambos and R. B. Livingston, UCSD, were generous in providing facilities at La Jolla.

\section{Methods}

The herring and lesser black-backed gulls (Larus argentatus and L. fuscus) were handreared from eggs, keeping them in semi-isolation for 5 weeks; this made them reasonably tame. Then they lived in large aviaries in groups of $6-8$, feeding on fish, meat and dog biscuits. Water was available in small ponds. When at least 8 months old, but always before they reached sexual maturity at the age of 3 years, they were implanted under pentobarbital anaesthesia (Delius, 1966a) with up to 8 stainless steel electrodes of $0.1 \mathrm{~mm}$ diameter and with $0.25 \mathrm{~mm}^{2}$ uninsulated tips. A subcutaneous bare wire served as the indifferent electrode (Delius, $1966 \mathrm{~b}$ ). After a week's recovery they were tested for $10-20$ sessions spread over 2-3 months in a $4 \mathrm{~m}^{3}$ cage. During each session each electrode was stimulated several times with 50 cycles sine wave current up to $200 \mu \mathrm{A}$. The brains were then conventionally processed and the electrode tips localized on sections stained for fibres and cells.

The domestic pigeons (Columba livia) of the white carneaux variety were adults from the Palmetto Pigeon Plant, North Carolina. Under Equithesin anaesthesia (Karten and Hodos, 1967) they were stereotactically implanted with staggered, multiple electrodes made of $0.2 \mathrm{~mm}$ diameter stainless steel wire with $0.5 \mathrm{~mm}^{2}$ uninsulated tips. A subcutaneous length of bare, stainless steel wire was used as indifferent electrode. Beginning some 5 days after the operation they were tested for 5-10 two hour sessions in their homecage, each eleetrode being repeatedly stimulated with 60 biphasic pulses per sec of $1 \mathrm{~ms}$ duration, and of up to 5 volts in strength. While usually the stimulation current was passed between the electrode tips and the indifferent (monopolar stimulation) in some cases the current was passed between two closely neighbouring electrode tips (bipolar stimulation). Electrode tips were located in conventionally prepared histological sections.

In both the gull and pigeon experiments it was made certain that the behavioural responses obtained were not incidental, but due to the stimulation itself, by randomly interposing control periods in which all the routine procedures of a stimulation trial were followed except that the bird was disconnected from the stimulator. Also in at least two trials for each electrode another bird was present in the testing cage to check for a possible communicatory role of the vocalizations elicited. 


\section{Results}

The results are presented separately for gulls and pigeons.

\section{Gulls}

Some 290 loci were stimulated in 50 birds. Of these only 8 sites yielded vocalizations. Anatomically, the positive sites fell in three groups: those located in the nucleus mesencephalicus lateralis dorsalis, those situated along the ventral edge of the nucleus intercollicularis and finally those associated with the nucleus posteromedialis hypothalami (Fig. 1).

Regarding the normal behaviour of the two closely related gull species with nearly identical behaviour (Goethe, 1955a; R. Brown, 1967) the reader is referred to Tinbergen $(1953,1959)$ and Goethe $(1956,1963)$. For identification of the stimulation-induced patterns I also made use of my own experience with the normal behaviour of these birds (Delius, 1970). It is important to note though that the behaviour of immature gulls differs quite markedly from that of adults (Goethe, $1955 \mathrm{~b})$.

One of the electrode tips located in the nucleus mesencephalicus lateralis dorsalis (431) yielded a brief eall with less than 250 msec latency. It was similar to calls normally given by the bird when suddenly frightened. Simultaneously the bird ran away towards the side contralateral to that stimulated. This response was reliable, occurring in 25 cases out of 30 supra-threshold stimulations. The threshold was at $50 \mu \mathrm{A}$ and varied little. Above threshold stimulation up to $120 \mu \mathrm{A}$ did not noticeably affect the quality of the call although the escape behaviour became more violent. Continuous stimulation did not elicit call repetition, this differing from the normal escape sequence where, if the frightening stimulus persisted, the gull would often repeat the vocalization. Repeated stimulation trials led only to a minimal rise in threshold once a refractory period of some $10 \mathrm{sec}$ had been allowed for. Within that period the bird reassumed its pre-stimulation behaviour. Repeated elicitation of the fright response did eventually have an aversive effect, in that it caused the gull to persist in escape attempts from the testing cage.

The other site (044), somewhat medial and ventral to the previous one, but still within the same nucleus, gave rise to a more graded alarm sequence. This consisted of a gradual neck stretching, sleeking of the plumage, and wide opening of the eyes elicited with $40 \mu \mathrm{A}$; a single alarm call, in 10 out of 15 trials, and a running or jumping backwards with extended wings with $60 \mu \mathrm{A}$. The call was identical to the characteristic alarm "keck" uttered by normal unstimulated gulls. Again it was not possible to elicit call repetition with continuous stimulation. An ap-

Fig. 1. Herring and lesser black-backed gulls. Locations at which electrode tips elicited vocalizations. More than 220 negative sites situated elsewhere in the brain have been omitted. For convenience all tip locations have been transferred to one brain side. Abbreviations: A archistriatum, AL ansa lenticularis, Cb cerebellum, CO chiasma opticum, CP comissura posterior, CT comissura tectalis, DS decusatio supraoptica, EW nucl. Edinger Westphal, FPL fasciculus prosencephali lateralis, Ico nucl. intercollicularis, Imc nucl. isthmi pars magnocellularis, IPc nucl. isthmi pars parvocellularis, MLD nucl. mesencephalicus pars dorsalis, $\mathrm{N}$ neostriatum, NC neostriatum caudale, OM tractus occipito-mesencephalicus, OMo nucl. nervi occulomtorii, PA paleostriatum augmentatum, PL nucl. pontus lateralis, PMH nucl. posteromedialis hypothalami, QF tractus quinto-frontalis, Rt nucl. rotundus, Ru nucl. ruber, SMe stria medullaris, TeO tectum opticum. Tpe nucl. tegmenti pedunculo pontinus pars compacta, $V$ ventriculus 


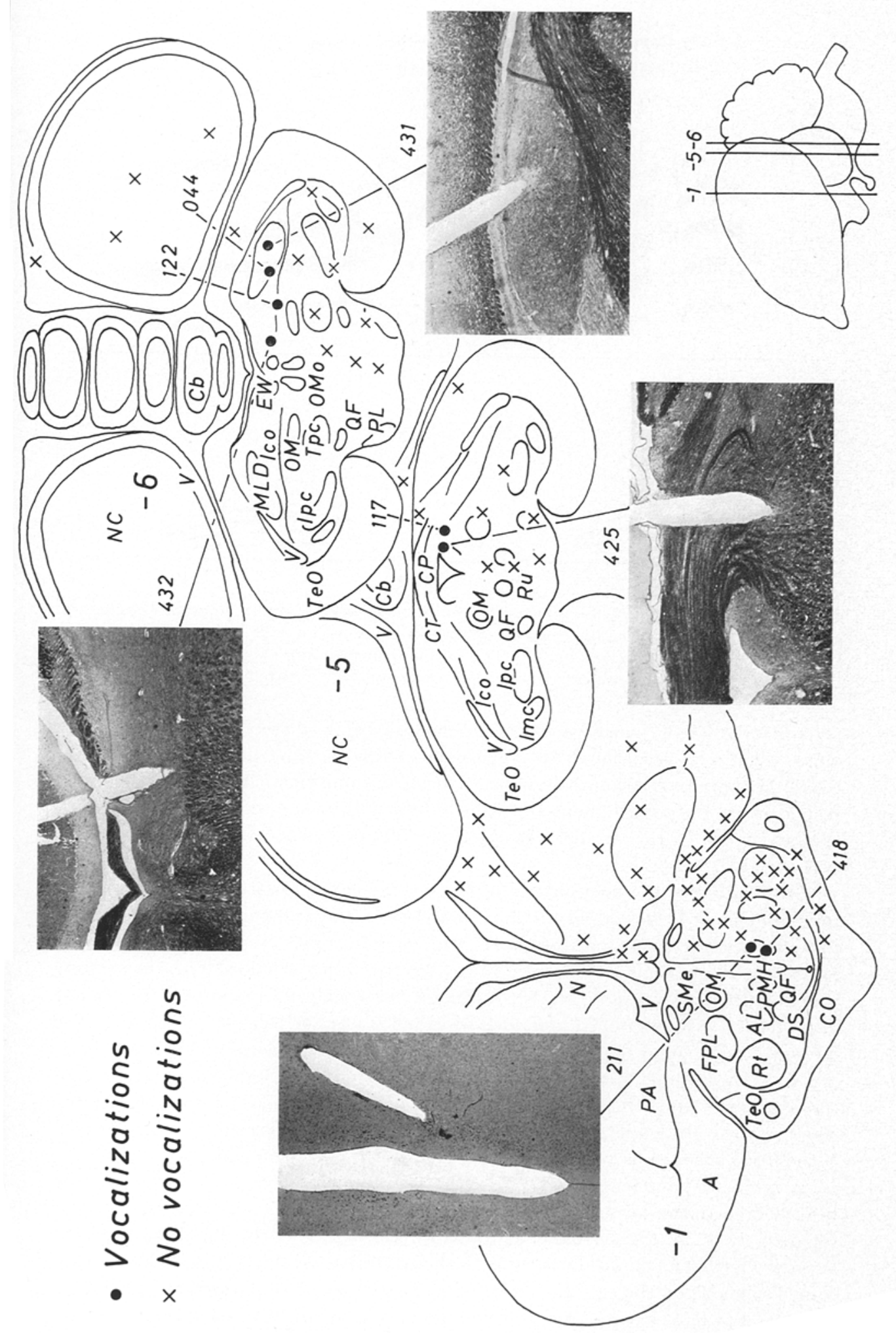



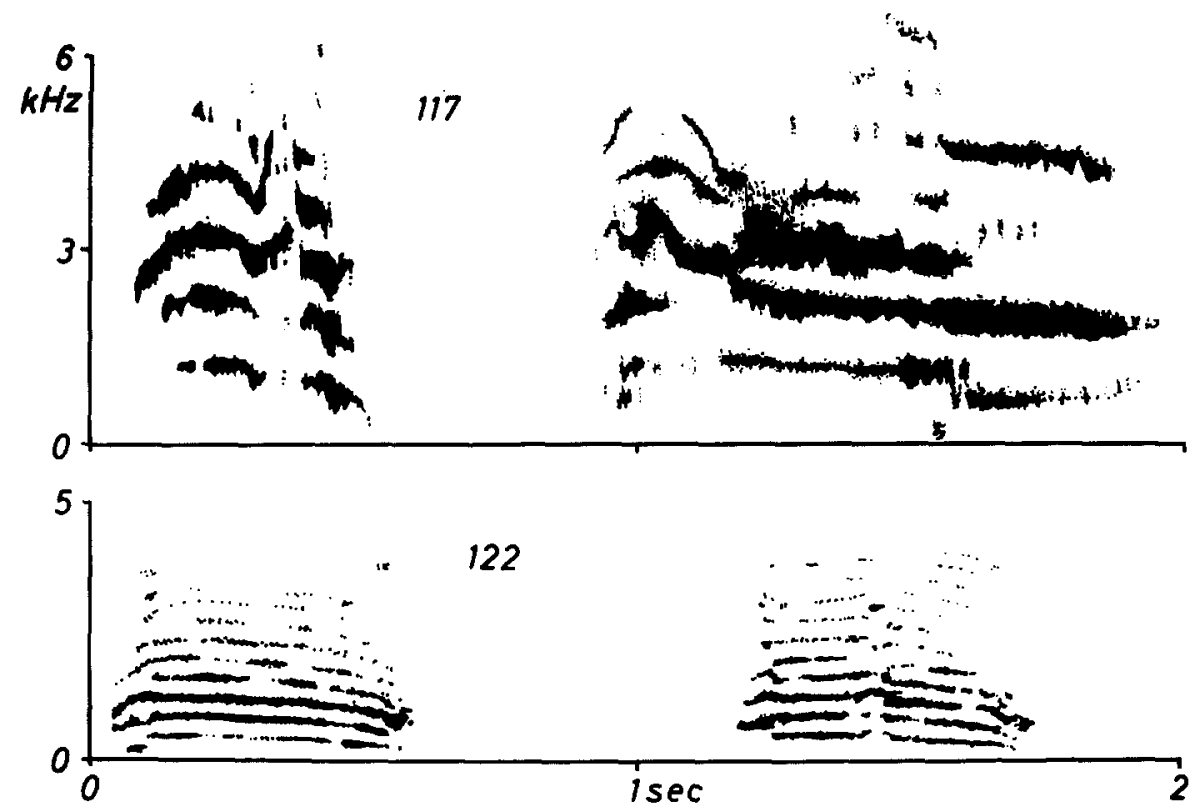

Fig. 2. Herring gulls and lesser black-backed gulls. Soundspectrograms of calls elicited from electrodes 117 and 122. The upper spectrogram was made with a wide-band filter setting, the lower with a narrow band setting. Goethe (1955a) illustrates sound-spectrograms of normal gull calls with which these can be compared

proximately 40 sec pause had to be interposed before a second stimulation train would elicit a vocalization. This corresponds with the time it took the animal to reassume pre-stimulation behaviour. During stimulation the animal remained responsive to the environment and adjusted its flight to some extent to the circumstances. At $90 \mu \mathrm{A}$ the latency was less than $250 \mathrm{msec}$, at less current it was longer and variable.

Stimulation of the most lateral of the loci along the lower edge of the nucleus intercollicularis (122) caused the bird to assume a body posture with an obliquely upward neck, a swollen throat and, with a wide open beak, to call repeated low pitched "quok-quok" syllables (Fig. 2 and 3). At threshold $(30 \mu \mathrm{A})$ the calling was unreliable ( 4 out of 10 trials). At $70 \mu \mathrm{A}$ the vocalization was reliable (12 out of 13 trials), higher pitched and with repeated faster syllables (15 in $15 \mathrm{sec}$ ). The latency was irregular, between less than 1 sec and 5 sec. Marked adaptation occurred with continuous stimulation. The bird remained noticeably alert for two or three minutes after stimulation. The call and posture elicited by the lower currents was similar to those seen often in adult birds before take-off, the function of which is to entice other gulls to fly off with them.

A more medial electrode (432) elicited the following behaviour: at $40 \mu \mathrm{A}$ the bird stretched the neck slightly and began with about 1 sec latency, to utter repetitively a call transcribable as "quia-quia". At above threshold currents the latency shortened and a slow turning to the contralateral side appeared. With continued stimulation the call was repeated as long as the stimulation lasted, at rates of up to 30 syllables per $15 \mathrm{sec}$, the rate increasing somewhat with stronger stimu- 
lation. The only after-effect of stimulation was an increase in alertness lasting several minutes. The call did vaguely resemble some of the component syllables of the long call, an advertizing vocalization, of immature birds.

Somewhat more posteriorly and medially another locus (117) gave a similar response. At threshold stimulation $(50 \mu \mathrm{A})$ the gull uttered, with an obliquely forward held head and a wide open beak, a repetitive (10 syllables per $15 \mathrm{sec}$ ), high pitched, variable "quia-quia" call (Fig. 2 and 4). The behaviour was reliably elicited when the gull was relaxed before stimulation (17 out of 17) but not when frightened beforehand; then the call could not be elicited even with above threshold currents ( 0 out of 5). Above threshold stimulation increased the rate of calling, so that at $80 \mu \mathrm{A}$, the syllables were drawn together into a continuous screech. This current however also elicited a violent homolateral turning together with head tilting and shaking. The latency, which at threshold varied between 5 and 8 sec, was reduced to less than 1 sec at $80 \mu \mathrm{A}$. During continuous stimulation there was rapid adapta-

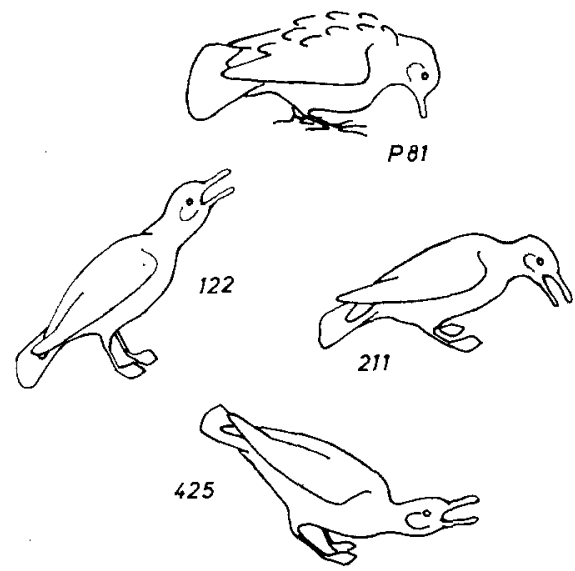

Fig. 3. Pigeons and herring and lesser black-backed gulls. Postures accompanying vocalizations elicited by electrodes P 81 (pigeon), 122, 211 and 425 (gulls)

tion which could be partially compensated by increasing the current. Paradoxically however, there was a marked and long lasting post-stimulus lowering of the vocalization threshold accompanied by behavioural relaxation (Fig. 5). In two instances a few syllables were given off as rebound. On three separate occasions the vocalization and the posture adopted was identical to the long call of immature gulls, but otherwise the resemblence was vague.

Close to the previous electrode another site (425), stimulated with $30 \mu \mathrm{A}$, caused the bird to immediately adopt a stooping posture with somewhat flexed legs and a forward stretched neck, and to pace about slowly (Fig. 3). At $40 \mu \mathrm{A}$ a repetitive, strangled call, was additionally obtained with $3-4$ sec latency on about half of the stimulation trials. At $50 \mu \mathrm{A}$ the call invariably accompanied the posture (15 cut of 15 trials). The latency was reduced to about 1 sec at this current level. Continuous stimulation led to repetitive but spaced calling with adaptation which could within limits, be compensated by increasing the stimulus: up to 14 syllables were obtained in this way within 15 sec. The posture and call could not easily be 


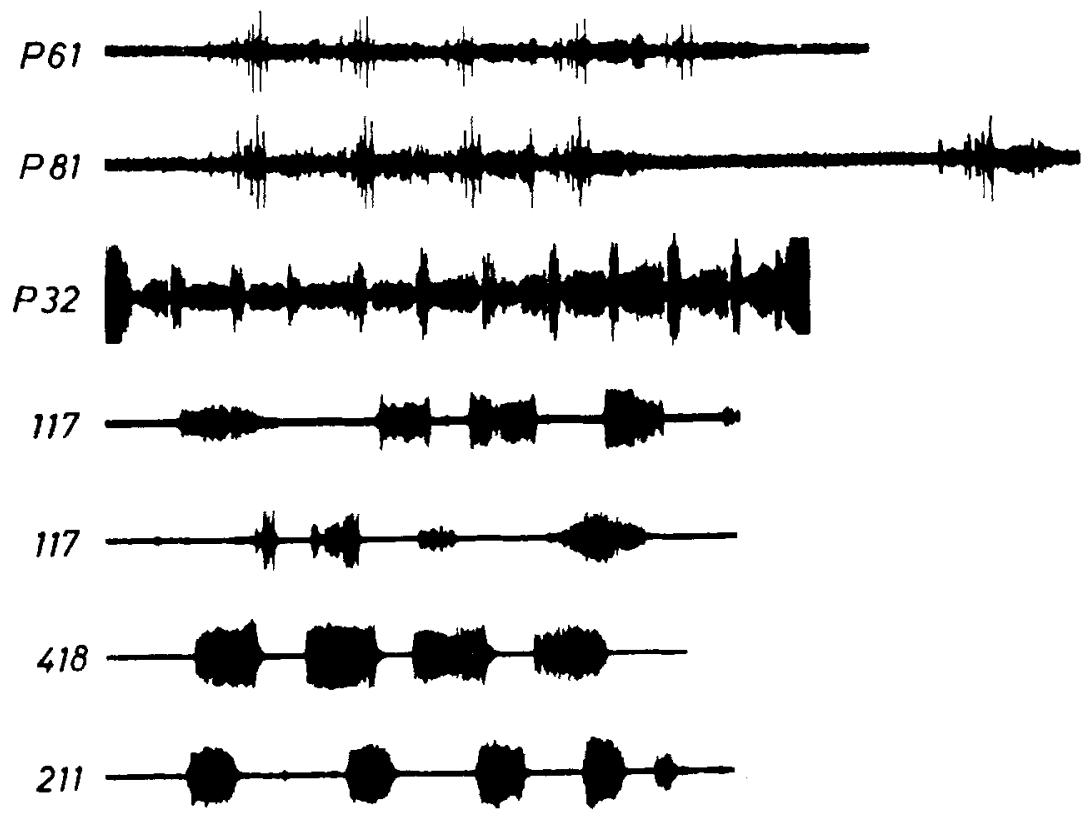

Fig. 4. Pigeons: upper three traces. Sound-oscillograms of the cooing elicited from electrodes P61, P81 and P32. Notice the similarity between P61 and P81. The burst at the end of the P81 trace represents the first coo of a second bout of 5 coos. On the P32 trace the initial burst represents the end of the word "on" spoken by the experimenter when switching the stimulator on. Notice the immediate onset of calling. The stimulus current was increased as the recording proceded. Herring and lesser black-backed gulls: lower four traces. Sound-oscillograms of calls elicited by electrodes 117,211 and 418. Notice the variability of the syllables elicited by electrode 117

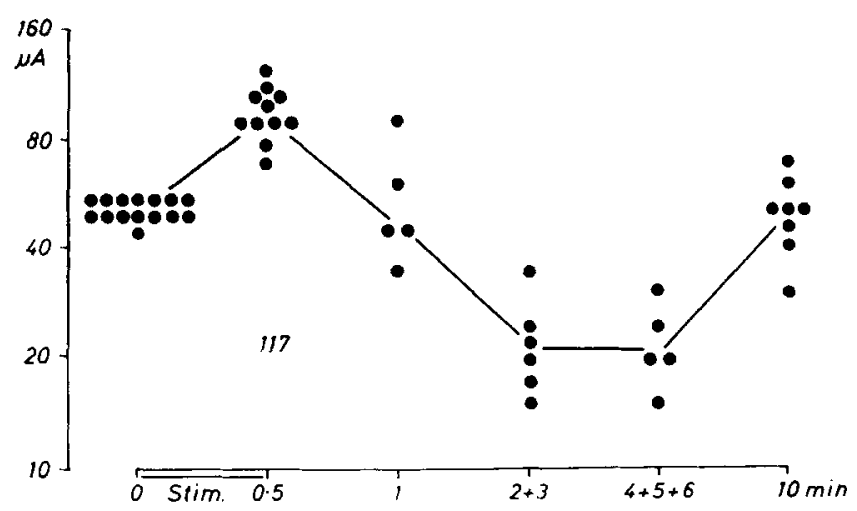

Fig. 5. Herring gull. Post-stimulus threshold depression for calling elicited from electrode $11 \%$. At 0 seconds the stimulus current was switched on for 24 trials and rapidly raised until calling began. The current was noted on 15 occasions, and then always maintained at a level adequate to ensure continued calling. This level was recorded on 11 instances as the stimulus was switched off after $30 \mathrm{sec}$ of stimulation. After 1,2,3, etc. min the threshold for calling was determined by rapidly and briefly increasing the current until calling occurred. In each trial only one threshold determination was made. The 24 trials were separated by at least $45 \mathrm{~min}$, sometimes by a day. The trend is significant at the $\mathrm{p}<0.01$ level according to a Kruskal-Wallis test. Notice that the scales are logarithmic (current) and nearly logarithmic (time) 
related to any normal behaviour; it is possible that the call was the normal alarm "keck" distorted by an unrelated posture. There were no detectable after-effects other than a slight tendency to squatt down.

One of the two electrodes located in the nucleus posteromedialis hypothalami (211) caused the gull to adopt a stooping posture with flexed legs and downwardpointing beak and to produce a repetitive call transcribable as "quak-quak" (Fig. 3 and 4). The threshold varied from session to session between $60-100 \mu \mathrm{A}$; within sessions it was stable. The response was reliable when the current was above the momentary threshold (18 out of 20). Sub-threshold stimulation caused the animal to show the neck shortening characteristic of a relaxed bird, but it only showed the stooping posture if the current was also sufficient to elicit the call. Administration of a tranquilizer (chloroprotixene, $5 \mathrm{mg}$ per $\mathrm{kg}$ bodyweight) raised the threshold of stooping and calling to $120-150 \mu \mathrm{A}$ but characteristically (St. Paul, 1965) did not affect the threshold of a turning response elicited by $120 \mu \mathrm{A}$. The latency was comparatively long and variable (4-11 sec) and was independent of the stimulus intensity. Marked adaptation, which could not be overcome by increasing the current, characterised this locus; 15 sec of maintained above threshold stimulation elicited maximally 8 calls before adaptation set in. The recovery from this adaptation took anything from a few minutes to apparently as long as $20 \mathrm{~min}$. A part from a mild post-stimulus relaxation there was no after effect.

Stimulation through the other electrode (418) at a threshold current of $40 \mu \mathrm{A}$ caused the gull to stretch the neck forward while pointing the beak slightly downward and to produce a repetitive "quak-quak" call similar to that elicited by electrode 211 (Fig. 4). There was a marked and persistent post-stimulus tendency to show escape behaviour; this was also shown during stimulation when currents were well above threshold. In these cases the call rate was accelerated, up to 13 syllables in $15 \mathrm{sec}$, and sometimes they became fused into a single screech. At low currents the call and the posture did have, as those produced by the previous electrode, a fleeting similarity with the courtship mew call of adult gulls.

\section{Pigeons}

10 birds were implanted with a total of 65 electrodes, 13 of which yielded vocalizations. Most of them were aimed at the nucleus mesencephalicus lateralis dorsalis and neighbouring structures. Fewer were directed at the nucleus posteromedialis hypothalamicus and neighbouring structures, but were unsuccessful except once. Accidentally, two were placed in or close to the nucleus ovoidalis and did elicit vocalizations (Fig. 6).

The reader is referred to Fabricius and Jansson (1963) for a description of the normal behaviour of pigeons.

10 loci in the nucleus mesencephalicus lateralis dorsalis and its neighbouring structures gave rise to vocalization upon monopolar stimulation. Additionally, 6 electrodes, which were ineffective in eliciting calls monopolarly, did produce calls when they were used as bipolar pairs. According to the responses the loci fell into two categories.

The majority of the electrodes ( 7 monopolar and 3 bipolar pairs) elicited only single, exceptionally 2 or 3 , cooing syllables with relatively high thresholds (3.5 to $4 \mathrm{~V}$ ) and were accompanied by a variety of escape behaviours such as flying off, 


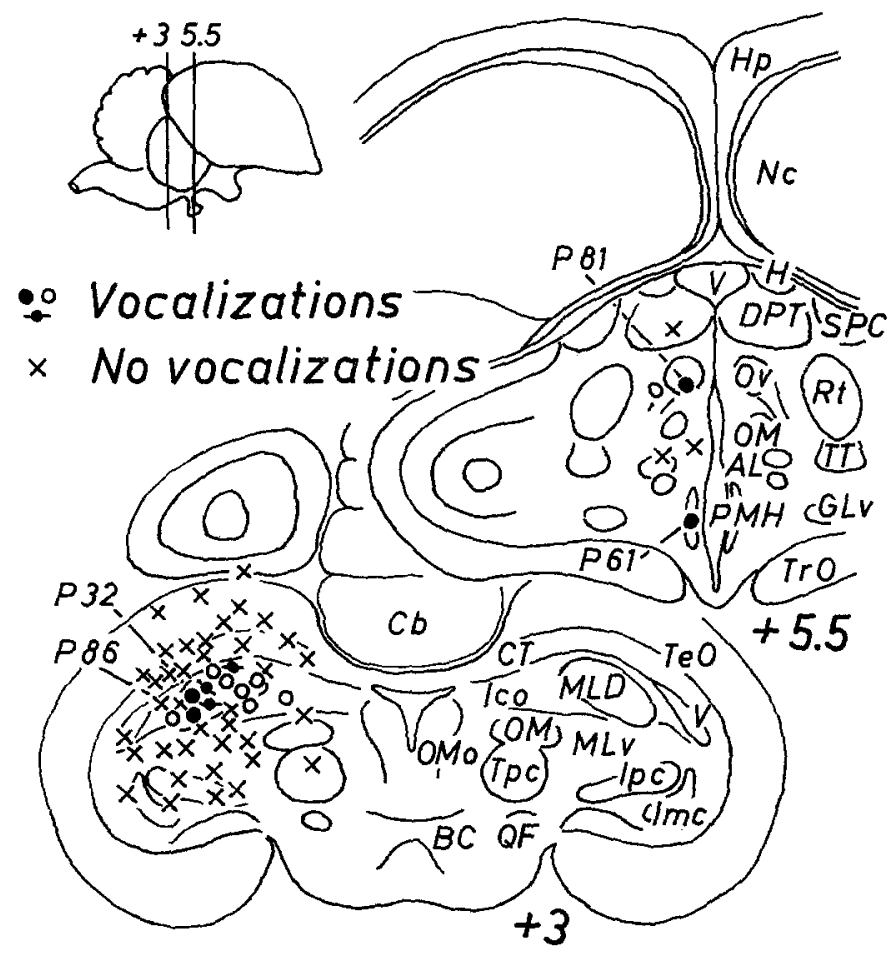

Fig. 6. Pigeons. Locations at which electrode tips elicited vocalizations. Some 10 negative sites situated elsewhere in the brain have been omitted. For convenience all electrode tips have been transferred to one side. Dots symbolize sites eliciting a repetitive vocalization. Circles those inducing single syllables, winged circles indicate midpoints between pair of tips which elicited single syllables when used as bipolar electrodes. Abbreviations are the same as in Fig. 1 and BC brachium conjunctivum, DPT nucl. dorsoposterior thalami, GLw nuel. geniculatus lateralis ventralis, $H$ habenula, $\mathrm{Hp}$ hippocampus, MLv nucl mesnecephalicus lateralis ventralis, $\mathrm{OV}$ nucl. ovoidalis, TrO tractus opticus, TT tractus tecto-thalamicus

jumping back or running forward. They were not very reliable in that suprathreshold stimulation would only give rise to the call in, for example, 4 out of 10 , or at best 10 out of 15 trials. Latencies were short, less than $250 \mathrm{msec}$ and varied little as far as it was ascertainable. The escape behaviour, seen in 5 out of the 10 electrodes, was directed towards the side ipsilateral to that stimulated. The detailed pattern of flight and turning was consistent for a given locus. The escape behaviour was reliably elicited at suprathreshold voltages even when the calls were absent. Although it could not be examined in enough detail, there appeared to be some adaptation to stimulation, this being reflected in a rise of thresholds with repeated stimulation trials. In 2 cases the calls could not be elicited at all after 2 initial testing sessions. This might have been due to the glia proliferation noticed around the track of some electrodes in the histological sections.

Two electrodes gave a different type of response: a continuous, maintained, repeated cooing. In one case ( $P 32)$ the component coo was similar, if not identical to those discussed in the previous paragraph (Fig. 4). Although at threshold current this was barely noticeable, at suprathreshold stimulation the call was accom- 
panied with escape behaviour comparable to that described previously, i.e., walking or jumping backwards with a tendency to turn to the ipsilateral side. The calling, incidentally could be obtained while the bird was still under anaesthesia. In the other case (P 86) the cooing was indistinguishable from that made by the same individual when engaged in aggressive encounters with conspecifics. However, apart from some restless walking about, no other behaviour accompanied the calling, except on 2 occasions out of 4 , where the pigeon began to attack its mirror image with wing flicks while stimulated. At twice threshold voltage the pigeon flew off backwards but did not then vocalize.

Both responses were highly reliable, provided the stimulation strength was suitable ( 15 out of 18,24 out of 26 trials respectively). Thresholds were comparatively low, $1-1.5 \mathrm{~V}$. Latencies were in both cases short, less than $250 \mathrm{msec}$. Cooing was continuous during extended stimulation and there was little adaptation. Calling stopped within 250 msec after the end of stimulation. The rate of repetition (at threshold 12-14 coos in 10 sec) as well as the loudness of cooing in both cases was slightly higher with above threshold voltages.

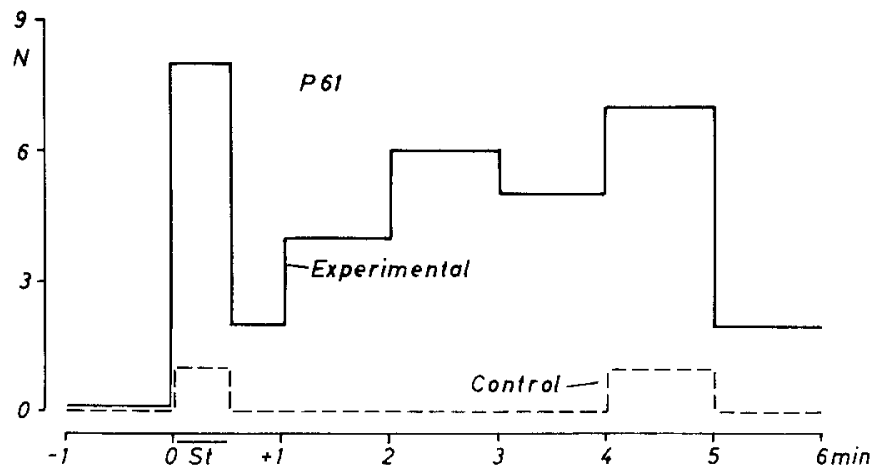

Fig. 7. Pigeon. Post-stimulus increase in vocalization probability elicited by electrode $P$ 61. $\mathrm{N}=$ number of vocalizations. After one control minute the bird was stimulated for 30 sec with the above threshold current which elicited vocalizations in 8 out of 10 trials and then the occurrence of calling was scored for the 30 sec period following and the subsequent one minute periods up to 6 min after the stimulation onset. The dashed line indicates the results of 10 control trials in which the stimulator was disconnected. Notice the delayed rebound peak in the probability of calling. During the trials other pigeons were present in the same room. If they were absent the post-stimulus effect was not noticeable although this condition did not affect

the elicitation of vocalization during stimulation

Of the sites in the nucleus ovoidalis and its surrounding areas, one electrode just lateral to the ovoidalis elicited one, or occasionally a few, distorted-sounding coos while the bird bowed before turning rapidly towards the side homolateral to that stimulated. The vocalization was unreliable (7 out of 18 trials); it appeared to depend on a delayed onset of the turning response. At any rate, when circling began the cooing was invariably terminated at once. The vocalization threshold was $1.6 \mathrm{~V}$.

The other electrode (P 81) placed within the nucleus itself yielded a bow-cooing ceremony. Coos were given in spaced bouts of 3-5 (Fig. 4) while the bird bowed sometimes after jerking forward, turning alternately from right to left while walk- 
ing about with small steps (Fig. 3). A slight preponderence for turning to the ipsilateral side was noticeable. The behaviour was in every way identical to the courtship the bird performed towards its mate when unstimulated. The threshold varied somewhat around $1.5 \mathrm{~V}$. There was some adaptation to the stimulation but this could be easily compensated by increasing the voltage. After 5- -8 bouts of cooing in about $60-90 \mathrm{sec}$, had been elicited in this way, it was not possible to elicit this behaviour again until some 3--4 min without stimulation had elapsed. The latency varied between 2 and 5 sec.

The single electrode located in the nucleus posteromedialis hypothalami ( $\mathrm{P}$ 61) elicited a bow-cooing sequence very similar to that just described (Fig. 4). The latency to the first vocalization however was extremely variable, between 2 and $15 \mathrm{sec}$. The bouts were also more spaced. No adaptation could be detected after a stimulation train, and provided that other pigeons were in the same room, the pigeon would persist in bow-cooing, with some interruptions, for up to $5 \mathrm{~min}$ or so (Fig. 7). This post-stimulatory facilitation did not however affect the threshold, which varied little around $2.2 \mathrm{~V}$. The reliability of the response was good, 15 out of 17 trials, except during one session where for no obvious reason no vocalization could be elicited in 5 trials. This response, incidentally was the only one which had an effect on other birds, in that they became visibly interested in the bird being stimulated.

\section{Discussion}

Popa and Popa (1933) first indicated that vocalizations could be obtained in pigeons by stimulating the nucleus mesencephalicus lateralis. This was confirmed for the red winged blackbird by J. Brown (1965a) who was also able to mute these birds by bilaterally lesioning this structure (J. Brown, 1965b). Murphey and Phillips (1967) and Putkonen (1967) have similarly shown that calling can be elicited from this structure in the chicken and Andrew (1969) mentions finding the same in the domestic chick. Maley (1969) presents concordant evidence for the mallard. These data together with my results, confirming Popa and Popa's findings for pigeons and indicating that they also apply to gulls, puts it beyond doubt that the nucleus mesencephalicus lateralis is involved in a variety of avian species in the generation of vocalizations.

While Popa and Popa, Murphey and Phillips, and Maley appear to differ, J. Brown's, Putkonen's and my own data indicate specifically the involvement of the large-celled pars dorsalis of the nucleus mesencephalicus lateralis ${ }^{1}$. This finding is remarkable in so far that, contrary to J. Brown's (1965a) conclusion based on unsatisfactory older evidence, the nucleus mesencephalicus lateralis dorsalis has been proved beyond doubt to be the avian homologue of the inferior colliculus. Boord (1968) has shown that lesions of the cochlear nucleus lead to terminal degeneration in this nucleus and Biederman Thorson (1967) has shown that its neurons are specifically responsive to sound.

One could attempt to explain the fact that vocalizations can be obained from stimulation of a main sensory nucleus by assuming that it causes auditory hallu-

${ }^{1}$ See also Potash (1970) and Allan (1970). These two important investigations came too late to my attention to be incorporated into this discussion. Their conclusions however are largely concordant with it. 
cinations, which in turn elicit calling. This explanation has difficulties: excepting the cooing of a pigeon I could find no other sound to be effective in eliciting even a single call. Even the cooing of a pigeon is a highly unreliable stimulus : in experiments where tape-recorded coos were played to pigeons, only in 2 out of 15 trials was a positive response obtained. Furthermore, the latencies between the onset of the stimulus calls and the response calls were quite long: $45 \mathrm{sec}$ in one and 150 sec in the other case. This contrasts markedly with the reliability and short latency of calling obtained with stimulation of the nucleus mesencephalicus lateralis dorsalis. The latencies were in fact shorter than indicated in that in the pigeons it was noticed that a definite inspiratory movement preceded sound emission and that often this occurred immediately after the stimulus current onset, that is within less than 100 msec. Andrew (1969) also indicates latencies of less than 100 msec for calling elicited from the inferior colliculus of domestic chicks. This suggests, as does the fact that calling from this area can be obtained even under anaesthesia (see also Murphey and Phillips, 1967), that a relatively direct motor pathway was being stimulated. Also, if hallucinations were the cause of the vocalizations elicited one would expect these to be calls from the normal repertoire of the species. This they were not: characteristically they sounded forced and unnatural.

It is puzzling that a motor pathway should originate in an auditory nucleus. An explanation could be derived from the assumption that vocalizations in birds are under a short-term auditory feedback control. This would require a confluence of sensory and motor pathways at a low level of the neuraxis. But Murphey and Phillips (1967) produced evidence that in chickens such feedback is not necessary; indeed, deafening affects neither the development nor the maintenance of species specific calls in chickens and doves. It is true though that some other bird species do require auditory feedback to acquire normal calling patterns, but none seem to need it to maintain them (Konishi and Nottebohm, 1969).

It seems reasonable to assume that the positive loci along the lower edge of the nucleus intercollicularis found in the gulls are associated with fibre pathways leading to and/or away from the inferior colliculus. The longer latencies and the more complex nature of the calls as compared with those elicited from the nucleus mesencephalicus lateralis seem to warrant the tentative conclusion that they are in fact afferent to it. Putkonen (1967), mentioning positive vocalization points in the region of the nucleus spiriformis of chickens, also associates them with stimulation of fibres of passage from and to the nucleus mesencephalicus lateralis dorsalis and more specifically with those linking the two inferior colliculi via the posterior commissure. Karten (1967), however, based on degeneration studies, describes the intercollicular fibres as passing through the commissura intertectalis. Examination of our own normal, fibre-stained pigeon and gull material indicates that apart from this connection there are, as described by Kappers, Huber and Crosby (1965), a considerable number of fibres terminating, or arising, in the nucleus mesencephalicus lateralis dorsalis which course among the cells of nucleus intercollicularis. Some of these can be followed into the posterior commissure and thus could account for Maley (1969) having obtained calls from this structure. Other fibres however, arise from areas close to the walls of the medial section of the third ventricle, and certain other of Maley's vocalization loci in mallards may have been due to stimulation of these latter axons. 
The accidental finding that stimulation of the nucleus ovoidalis can reliably elicit a vocalization in conjunction with the corresponding courtship display in the pigeon is partially consonant with the findings of other workers. Both Maley (1969) in mallards, and Putkonen (1967) in chickens, report circumovoidal loci which gave rise to vocalizations although in the context of agonistic responses. Whatever the context, these results are as puzzling as those obtained from the inferior colliculus, since Karten $(1967,1968)$ using degeneration techniques has shown this nucleus to be the avian homologue of the mammalian medial geniculate. Biederman Thorson (pers. comm.) has confirmed this by demonstrating electrophysiologically that it is a specific auditory nucleus.

As in the case of the nucleus mesencephalicus lateralis dorsalis, the functional significance of the fact that an auditory sensory nucleus may be involved in the motor control of vocalizations and displays is not obvious. But further discussion of this may be premature until it is confirmed that it is in effect the nucleus ovoidalis, and not the fibre tracts which surround it, which is responsible for the effect in question. Maley specifically suspects the tractus occipito-mesencephalicus: it courses in the neighbourhood of the nucleus ovoidalis and it has been implicated at more cephalad levels including its origin, the archistriatum, with the control of vocalizations and agonistic displays by Akerman (1966) in pigeons, Putkonen (1967) in chickens and Maley (1969) in mallards.

The finding that calling can be obtained both in gulls and pigeons by stimulating the nucleus posteromedialis hypothalami fits in well with Akerman's (1966) data for pigeons. He found that vocalizations in the contexts of agonistic and courtship displays could be obtained from a number of periventricular preoptic and hypothalamic nuclei including the posteromedialis hypothalami. Maley (1969) confirms this for mallards regarding calling in agonistic contexts and also presents results which extend this periventricular area to include the substantia grisea centralis of the mesencephalon.

Tentatively and as a working hypothesis I suggest that the fibres, coursing through the nucleus intercollicularis and terminating in the nucleus mesencephalicus lateralis dorsalis, originate in the periventricular preoptic, hypothalamic and perhaps even mesencephalic nuclei, the nucleus posteromedialis hypothalami among them. Kappers, Huber and Crosby (1965) further indicate that components of the tractus occipito-mesencephalicus terminate in these nuclei; this would incorporate the circumovoidal, occipito-mesencephalic and archistriatal vocalization activating sites into a linearly organized system.

Even while proposing this scheme, I believe that it does not adequately reflect the real complexity of the vocalization substrate. Akerman (1966), for example, obtained vocalization in a display context in pigeons from the region of the nucleus accumbens. His data suggests that the nucleus accumbens acts so through afference to the preoptic periventricular nuclei. Stimulation of the nucleus accumbens in gulls did indeed elicit a threat-courtship display, but it was not accompanied by any vocalization (Delius, in prep.). J. Brown (1969) in his review also underlines the evidence for a relative functional differentiation of the areas mentioned in terms of the behavioural context in which the calls elicited by stimulation are given. 
It is interesting to note here that although the tractus occipito-mesencephalicus and the archistriatum was stimulated at various points in gulls none of these loci elicited vocalizations, nor for that matter any clearcut agonistic displays. This may be associated with the sexual immaturity of the experimental birds, or rather with their hormonal state. Barfield (1965) found that in chicken capons implants of androgens in the region of the archistriatum and the occipito-mesencephalic tract facilitated aggressive responses. Hutchison (1967) demonstrated that similar implants in the nuclei medialis preopticus and hypothalamicus posteromedialis reinstate courtship behaviour with adequate vocalizations in castrated male doves. The probable absence of hormone facilitation at these levels in juvenile gulls may thus explain the fact that vocalization could not be obtained from any forebrain loci. Indeed, the immature gulls were strikingly silent compared with adult birds living in the same conditions.

The action of the hormones is probably more than simply facilitatory since stimulation of the nucleus posteromedialis hypothalami in the pigeon elicits a well organized courtship display with the corresponding call, whilst in the gulls stimulation of the same nucleus does not produce any clearly recognizable display and call complex, indeed, even the vocalizations could not be related with any certainty to normal ones.

The role of sexual hormones may also be reflected in the fact that of the 6 gulls and 6 pigeons which had electrodes yielding vocalizations, 5 and 4 respectively were males, even though both sexes were nearly equally represented among the 50 gulls and the 10 pigeons used in these experiments. All the females which vocalized on stimulation did so from electrodes in the inferior colliculi.

The proposed efferent system : archistriatum, tractus occipito mesencephalicus, periventricular nuclei, inferior colliculus, can tentatively be further extended to medullar levels. Murphey and. Phillips (1967), based on fibre degeneration studies in chickens, indicate, but unfortunately do not describe, a descending pathway from the area of the nucleus mesencephalicus dorsalis ending ipsi- and contralaterally in the ventromedial pons and medulla. They also present some electrophysiological data supporting its involvement in the motor control of vocalization. Karten (1967) describes a similar tract in pigeons ending in the ipsilateral corpus trapezoideus. The course of this latter tract through the lateral mesencephalic reticular formation would explain Maley's (1969) finding that stimulation of this region sometimes elicits vocalization in escape behaviour contexts in mallards, but the termination in the trapezoid body does of course not agree well with a motor function.

The fact that lesions in the inferior colliculi completely silences red winged blackbirds (J. Brown, 1965b) and chickens (Phillips, pers. comm.), however, suggests that whatever the course of the efferent pathways this structure does represent the final common pathway for all vocalizations, irrespective of the behaviour context in which they are produced. The objection that stimulation of this structure only elicits alarm calls and that therefore the nucleus mesencephalicus lateralis is only concerned with fear related vocalizations ( $\mathrm{J}$. Brown, 1965a; Maley, 1969) is weakened by my finding that it is possible to elicit aggression related calls in pigeons from this structure. 
The neural system suggested corresponds reasonably well with that mediating vocalizations in mammals as described by Hunsperger (1965), Robinson (1967), Jürgens and Ploog (1970). Regarding the involvement of the avian inferior colliculus, Kanai and Wang (1962) noticed a marked difference in the quality of the miawing of cats elicited from points in the mesencephalic periventricular grey anterior to the deep inferior colliculi in comparison with that produced by stimulation points posterior to them among reticular nuclei. The vocalizations elicited. from this latter area were continuous and unstructured, whereas those from the former region were patterned like those normal of cats.

The little data as yet available on amphibians (Schmidt, 1966, 1968; Potter, 1965) seems to indicate that this organisational pattern may be indeed of a long phylogenetic standing:

I found, in agreement with Robinson's (1967) extensive data on macaques, no evidence for laterality. 7 of the call-eliciting electrodes in pigeons were located in the left, and 6 in the right side of the pigeon's brains, while the corresponding figures for the gulls were 4 and 4 . Nottebohm (1970), however, based on a functional assymetry of the nervi hypoglossi innervating the syrinx, has inferred a laterality in the central mechanisms of singing of the chaffinch.

As a final point I wish to draw attention to the heterogeneity in time-dynamic characteristics of the vocalization-eliciting loci. Even electrodes located in nearly identical loci often showed widely differing properties in terms of latency, persistence, adaptation, recovery, facilitation ete. From own experience with movable electrodes (Delius, 1966b) in other contexts it is obvious that often these properties are drastically dependent on minimal differences in electrode tip position. Presumably this reflects the activation of different, non-equivalent pools of neurons which form part of the network responsible for the response stimulated. Whatever the explanation, it warns against assuming that such properties are characteristic for a given structure when it operates during behaviour aroused in a nurmal way (von Holst and Saint Paul, 1960; but see Harwood and Vowles, 1967).

\section{References}

Akerman, B.: Behavioural effects of electrical stimulation in the forebrain of the pigeon. Behaviour 26, 323-350 (1966).

Allan, N.B.: Central mechanisms of chick vocalizations. Ph. D. thesis. Brighton: University of Sussex 1970.

Andrew, R.J.: Intracranial self-stimulation in the chick and the causation of emotional behaviour. Ann. N. Y. Acad. Sci. 159, 625-639 (1969).

Barfield, R.J.: Induction of aggressive behaviour and courtship behaviour by intracerebral implants of androgen in capons. Amer. Zool. 5, 203 (1965).

Biederman Thorson, M.: Auditory responses of neurons in the lateral mesencephalic nucleus (inferior colliculus) of the barbary dove. J. Physiol. (Lond.) 193, 695-705 (1967).

Boord, R.L.: Ascending projections of the primary cochlear nuelei and nucleus laminaris in the pigeon. J. comp. Neurol. 133, $523-542$ (1968).

Brown, J.L.: Vocalization evoked from the optic lobe of a songbird. Science 149, 1002-1003 (1965a).

- Loss of vocalization caused by lesions in the nucleus mesencephalicus lateralis of the redwinged blackbird. Amer. Zool. 5, 693 (1965 b).

- The control of avian vocalization by the central nervous system. In: Hinde, R.A. (ed), Bird Vocalization. Cambridge: University Press 1969. 
Brown, R.G.B.: Species isolation between the herring gull and lesser black-backed gull. Ibis 109, 310-318 (1967).

Delius, J.D.: Pentobarbital anaesthesia in the herring and lesser black-backed gull. J. small Anim. Pract. 7, 605-609 (1966a).

- Some techniques for the electrical brain stimulation of small unrestrained animals. Med. biol. Enging. 4, 393-397 (1966b).

- Displacement activities and arousal. Nature (Lond.) 214, 1259-1260 (1967).

- The effect of daytime, tides and other factors on some activities of lesser black-backed gulls, Larus fuscus. Rev. comp. Anim. (1970) [in press].

Fabricius, E., Jansson, A.: Laboratory observations on the reproductive behaviour of the pigeon (Columba livia) during the preincubation phase of the breeding cycle. Anim. Behav. 11, 334-347 (1963).

Goethe, F.: Vergleichende Beobachtungen zum Verhalten der Silbermöwe (Larus argentatus) und der Heringsmöwe (Larus fuscus). Acta XI Congr. Int. Orn. 1954, 577-582 (1955a).

- Beobachtungen bei der Aufzucht junger Silbermöwen. Z. Tierpsychol. 12, 402-433 (1955b).

- Die Silbermöwe, Wittenberg: Ziemsen 1956.

- Verhaltensunterschiede zwischen europäischen Formen der Silbermöwengruppe. J. Ornith. 104, 129-141 (1963).

Greenwalt, C.H.: How birds sing. Scient. Amer. 221, 126-139 (1969).

Haarwood, D., Vowles, D.M.: Defensive behaviour and the after effects of brain stimulation in the ring dove. Neuropsychologia 5, 345-366 (1967).

Hinde, R.A.: (ed). Bird Vocalization. Cambridge: University Press 1969.

Holst, E. von, St. Paul, U. von: Vom Wirkungsgefüge der Triebe. Naturwissenschaften 47, $409-422(1960)$.

Hunsperger, R.W.: Neurophysiologische Grundlagen des affektiven Verhaltens. Bull. schweiz. Akad. med. Wiss. 21, 8-22 (1965).

Hutchison, J. B.: Initiation of courtship by hypothalamic implants of testosterone propionate in castrated doves. Nature (Lond.) 216, 591 -592 (1967).

John Smith, W.: Messages of vertebrate communication. Science 165, 145-150 (1969).

Jürgens, U., Ploog, D.: Cerebral representation of vocalization in the squirrel monkey. Exp. Brain Res. 10, 532-554 (1970).

Kappers, C.U.A., Huber, G.C., Crosby, E.C.: The comparative anatomy of the nervous system of vertebrates including man. New York: Hafner 1965.

Karten, H. J.: The ascending auditory pathways in the pigeon. I. Diencephalic projections of the inferior colliculus (nucleus mesencephalicus lateralis, pars dorsalis). Brain Res. 6, 409-427 (1967).

- The ascending auditory pathways in the pigeon. II. Telencephalic projections of the nucleus ovoidalis thalami. Brain Res. 11, 134-153 (1968).

- Hodos, W.: A stereotaxic atlas of the brain of the pigeon (Columba livia). Baltimore: Johns Hopkins Press 1967.

Kanai, T., Wang, S.C.: Localization of the central vocalization mechanism in the brain stem of the cat. Exp. Neurol. 6, 426-434 (1962).

Konishi, M., Nottebohm, F.: Experimental studies in the ontogeny of avian vocalizations. In: Hinde, R.A. (ed), Bird Vocalization. Cambridge: University Press 1969.

Maley, M.J.: Electrical stimulation of agonistic behaviour in the mallard. Behaviour 34, 138-160 (1969).

Murphey, R.K., Phillips, R. E.: Central patterning of a vocalization in fowl. Nature (Lond.) 216, $1125-1126$ (1967).

Nottebohm, F.: Ontogeny of bird song. Science 167, 950-956 (1970).

Popa, G. T., Popa, F.G.: Certain functions of the midbrain in pigeons. Proc. roy. Soc. B 113, $191-195(1933)$.

Potash, L.M.: Vocalizations elicited by electrical brain stimulation in Coturnix coturnix japonica. Behaviour 36, 149-167 (1970). 
Potter, H.D.: Mesencephalic auditory region of the bullfrog. J. Neurophysiol. 28, 1132-1154 (1965).

Putkonen, P.T.S.: Electrical stimulation of the avian brain. Ann. Acad. Sci. fenn. A 130, $1-95(1967)$.

Robinson, B.R.: Vocalizations evoked from forebrain in Maccaca mulatta. Physiol. Behav. 2, $345-354$ (1967).

St. Paul, U. von: Einfluß von Pharmaka auf die Auslösbarkeit von Verhaltensweisen durch elektrische Reizung. Z. vergl. Physiol. 50, 415-466 (1965).

Schmidt, R.S.: Central mechanisms of frog calling. Behaviour 26, 251—285 (1966).

- Preoptic activation of frog mating behaviour. Behaviour 30, 239-257 (1968).

Thorpe, W.H.: Bird Song. Cambridge: University Press 1958.

Tinbergen, N.: The Herring Gull's World. London: Collins 1953.

- Comparative studies of the behaviour of gulls. Behaviour 15, l-70 (1959).

Dr. Juan D. Delius

Dept. of Psychology

University of Durham

South Road

Durham (England) 